\title{
T7 vertebral burst fracture with left pedicle separated from vertebral body and displaced in vertebral canal without neurologic deficits in a 12 years old motorbike competition rider
}

\author{
Marco Crostelli ${ }^{1}$, Osvaldo Mazza ${ }^{1 *}$, Massimo Mariani ${ }^{1}$, Pietro Persiani ${ }^{2}$, Filippo Maria Ranaldi ${ }^{2}$, Dario Mascello and Carlo Iorio $^{1}$ \\ ${ }^{1}$ Spine Surgery Unit, Surgery and Transplants Department, Ospedale Pediatrico Bambino Gesù, Roma, Italy \\ ${ }^{2}$ Department of Anatomic, Histologic, Forensic and Locomotor Apparatus Sciences, "Sapienza" University, Roma, Italy
}

\begin{abstract}
Introduction: CL, aged 12 years and 4 months, suffered multiple thoracic spine fractures in an accident as a rider in motorbike competition reporting T7 body fracture with anterior wedging associated with displaced left pedicle fracture at level of vertebral body- pedicle union, pedicle was displaced inside vertebral canal completely obliterating sub arachnoid space. There were associated T5, T6, T8, T9, T10 body wedge fractures. Imaging shown no sign of spinal cord lesion. Clinical exam shown no nervous deficits.

Material and Methods: Treatment strategy had two goals, initial T7 fracture stabilization and nervous structures decompression. After initial stabilization with pedicle screws inserted in T5, T6, T8 and T7 vertebras, and only right-side rod mounted, we performed T6 and, partially, T7 left laminotomy: this manoeuvre allowed the direct visualization of left pedicle fragment with facet joint dislocated in the vertebral canal and compressing lateral surface of dural sac. The fragment was accurately isolated from sac surface and removed; no dural lesion showed after fragment removal, the dural sac regained its original dimension. Left rod is inserted, we performed transverse left side T6-T7-T8 arthrodesis and posterior right side T6-T7-T8 arthrodesis. Intra operatory neurophysiologic monitoring is performed during all operation, with continuous normal signal passage. After surgery patient neurologic exam was unchanged.

Patient is braced by cast and set up three days after surgery. 30 days after surgery cast is substituted by custom brace that patient wears continuously for 2 months.

Nine months after surgery T6-T7-T8 arthrodesis is complete on $\mathrm{x}$-rays exam and instrumentation is removed

One year after stabilization patient has regained all his previous life activities, even motorbike competitions, with new motorbike accident and left tibial plate fracture.

Discussion: As children motorbike use and competitions are becoming more and more diffuse, motorbike accidents with resulting lesions are more common, including severe spine fractures. The patient of this case report is included in a cohort of 6 cases of thoracic fractures caused by injuries during young riders' motorbike competitions in patients under 15 years of age. Two of them have been treated by surgery and the other 4 patients have been treated by cast/bracing without surgery.
\end{abstract}

\section{Introduction}

Spine injuries in children are rare, and thoracolumbar spine fractures account for 1 to $2 \%$ of all paediatric fractures [1-4]. The most common cause of thoracolumbar paediatric spine trauma is motor vehicle accidents, which account from 33 to $58 \%$ of all fractures $[3,5,6]$. The increasing diffusion of the use of all-terrain vehicle (ATV) for leisure or competition for very young driver is a major cause of paediatric thoracolumbar spine injury $[7,8]$. Children and adolescent under 16 years of age represent a large percentage of all-terrain vehicles (ATV) accidents victims (25 to $31 \%$ ) in United States statistic [9]. Children and adolescent driver are often improperly taught and lack the appropriate knowledge to ride safely [10], in addition, they are often not physically strong enough to avoid injury and may not have fully developed motor skills and ability for reasonable judgment [11]. Spine injuries in paediatric patients account for $7.4 \%$ of all ATV accidents injuries and the number of children who sustained ATVrelated injuries increased 476\% between 1997 and 2006 [8]. Thoracic spine is interested in $39 \%$ of spine fractures related to ATV accidents in children [9].

\section{Material and methods}

CL, aged 12 years and 4 months, amateur motocross rider, fell from his AT bike during an organized motocross race, reporting thoracic spine injury. On accident scene he complained of dorsal pain, his neurologic exam was completely normal. He has been placed on spine axis and transported to first treatment hospital, where he has been studied by plain $\mathrm{x}$ rays, CT scan and MRI of spine, revealing T7 vertebra body fracture with anterior wedging, associated to dislocated fracture of left pedicle united with left facet joint: the pedicle was separated from

${ }^{\star}$ Correspondence to: Osvaldo Mazza, Spine Surgery Unit, Surgery and Transplants Department, Ospedale Pediatrico Bambino Gesù, Roma, Italy, E-mail: osvaldo.mazza@opbg.net; osvaldo.mazza1973@hotmail.it

Key words: spine trauma, pediatric vertebral fracture, pediatric spine surgery, spine lesions in motorbike accidents in pediatric population

Received: November 20, 2018; Accepted: December 20, 2018; Published: December 28, 2018 
vertebral body at level of vertebral body-pedicle union and dislocated inside vertebral canal, completely obliterating sub arachnoid space (Figure 1); RMN shown no signs of spinal cord injury or compression by displaced fragment.

There were associated T5, T6, T8, T9, T10 vertebral body compression fractures with anterior wedging. The patient still had no nervous impairment.

The patient has been referred to our Spine Unit where treatment strategy had two goals: initial T7 fracture stabilization and nervous structures decompression. After initial stabilization with pedicle screws inserted in T5, T6, T8 and T7 vertebras, and only right-side rod mounted, we performed T6 and, partially, T7 left laminotomy (Figure 2): this manoeuvre allowed the direct visualization of left pedicle and facet joint fragment dislocated in the vertebral canal and compressing dural sac. The fragment was accurately isolated from sac surface and removed "en bloc" (Figure 2); no dural lesion showed after fragment removal, the dural sac regained its original dimension. Left rod is inserted: we performed transverse left side T6-T7-T8 arthrodesis and posterior right side T6-T7-T8 arthrodesis. Instrumentation is completed by two transverse connectors to increase rigidity. Intra operatory neurophysiologic monitoring is performed during all operation, with continuous normal signal passage. After surgery patient neurologic exam was unchanged.
Patient is braced by cast and set up three days after surgery and begin walking without aid. 30 days after surgery cast is substituted by custom brace that patient wears continuously for 2 months. After this period the brace is discontinued, and patient is encouraged to restart light physical activity, like swimming. Patient did not complain of any spine pain, except a vague harassment in the arthrodesis area, due to slightly protruding instrumentation.

Nine months after surgery T6-T7-T8 arthrodesis is complete on $\mathrm{x}$-rays exam and instrumentation is removed (Figure 3 ).

One year after stabilization patient has regained all his previous life activities, even motorbike competitions, with new motorbike accident and tibial plate fracture (Figure 3). He has no pain at all and does not complain any stiffness or limitation in spine movements.

\section{Discussion}

Paediatric spine anatomy is peculiar: compared with adults, children have greater ligamentous flexibility and elasticity, more horizontal articular facets, and relative paraspinal muscles immaturity [5]. As in adults, ribs help to prevent significant dislocations in the thoracic spine [3]; however, young patients have less protection from overlying muscles and bony structures. In compression injuries, a preponderance of multilevel injuries in children may be attributable to increased flexibility and small vertebral bodies allowing only small
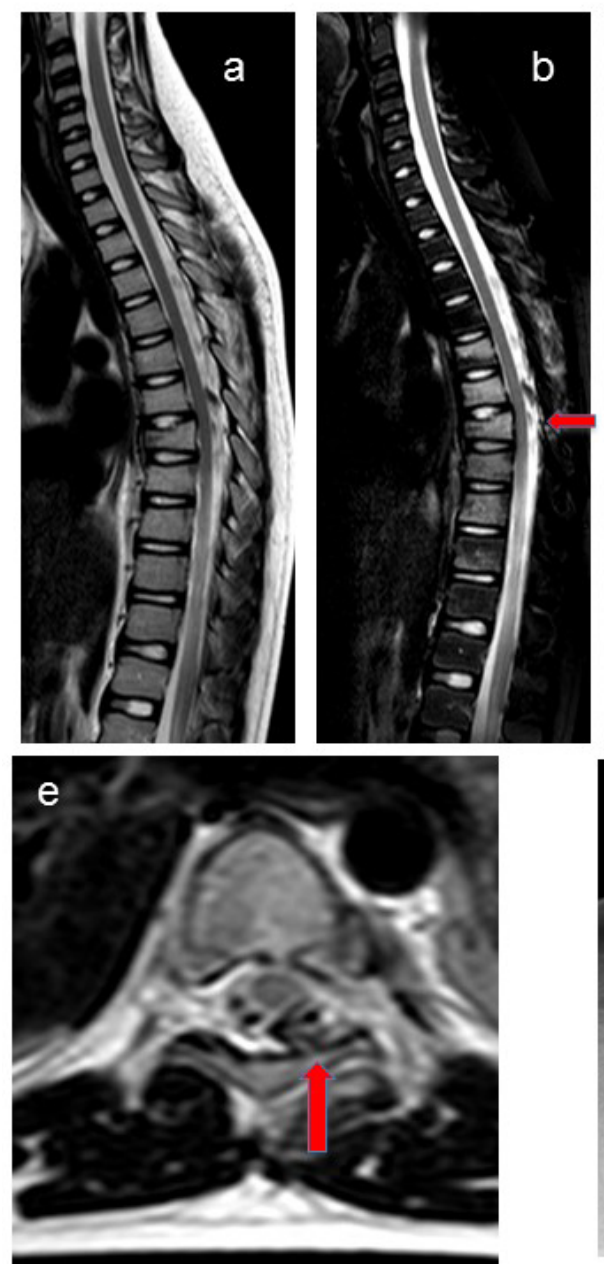
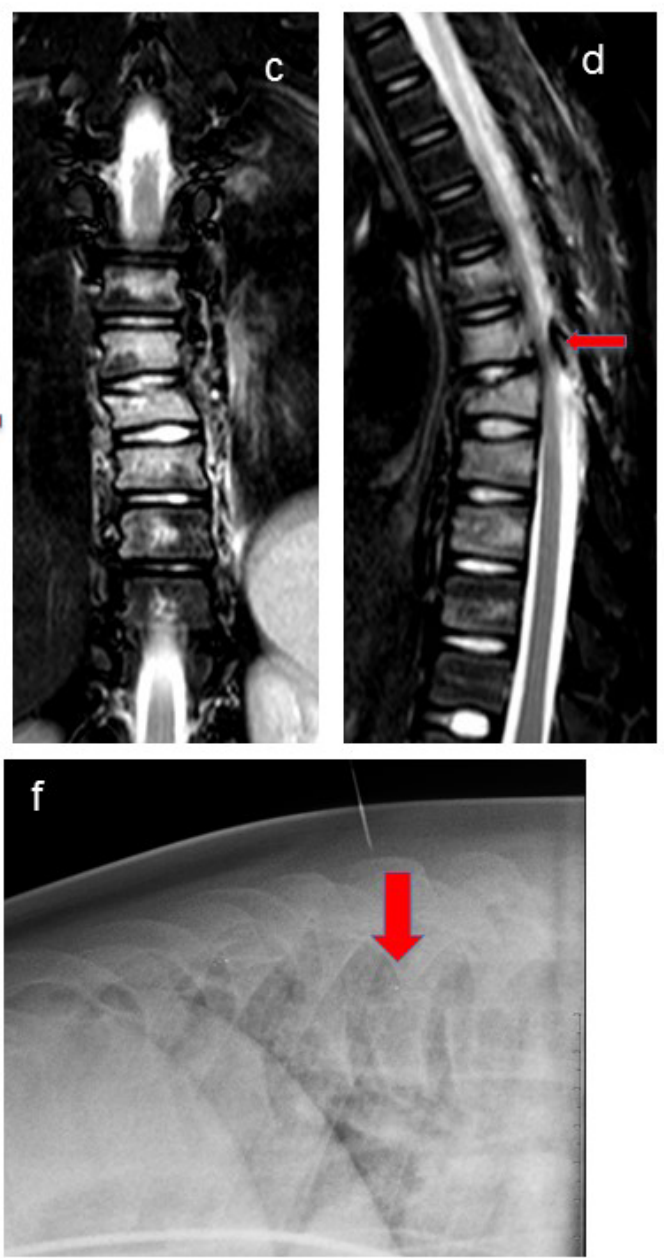

Figure 1. CL a, b, c: MRI showing T7 burst fracture, T5,T6, T8, T9, T10 anterior wedging with bone edema, no ischemic compression on nervous structures; d, e: MRI showing T7 left pedicle dislocated inside vertebral canal; f: Lateral X-ray before surgery showing $\mathrm{T} 7$ anterior body wedging 
Crostelli M (2018) T7 vertebral burst fracture with left pedicle separated from vertebral body and displaced in vertebral canal without neurologic deficits in a 12 years old motorbike competition rider

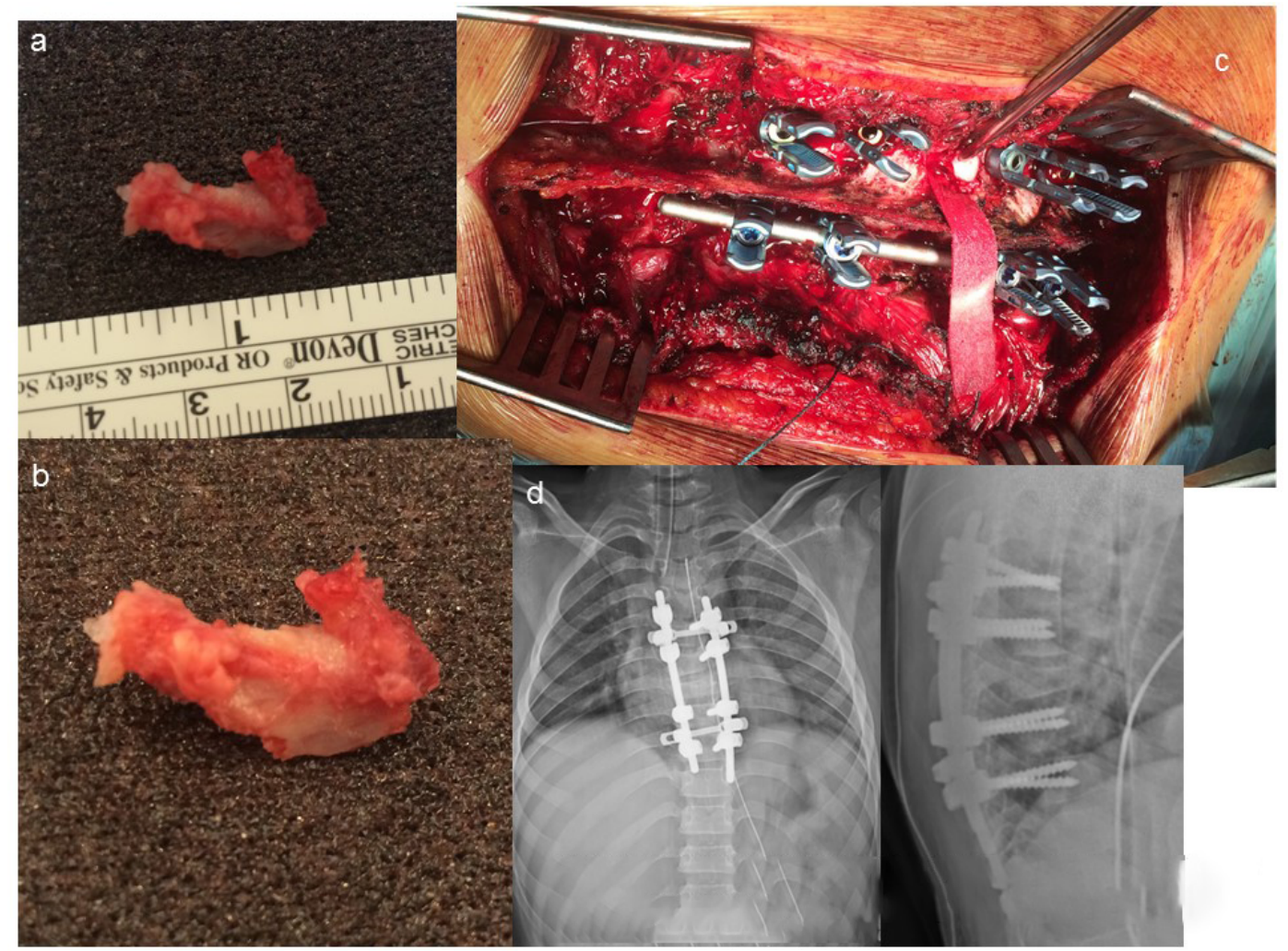

Figure 2. a, b: T7 left pedicle dislocated fragment removed from vertebral canal; c: Initial stabilization with pedicle screws inserted in T5, T6, T8 and T7 vertebras, and only right-side rod mounted T6 and, partially, T7 left laminotomy dural sac decompressed after T7 pedicle removal; d: X-rays after surgery
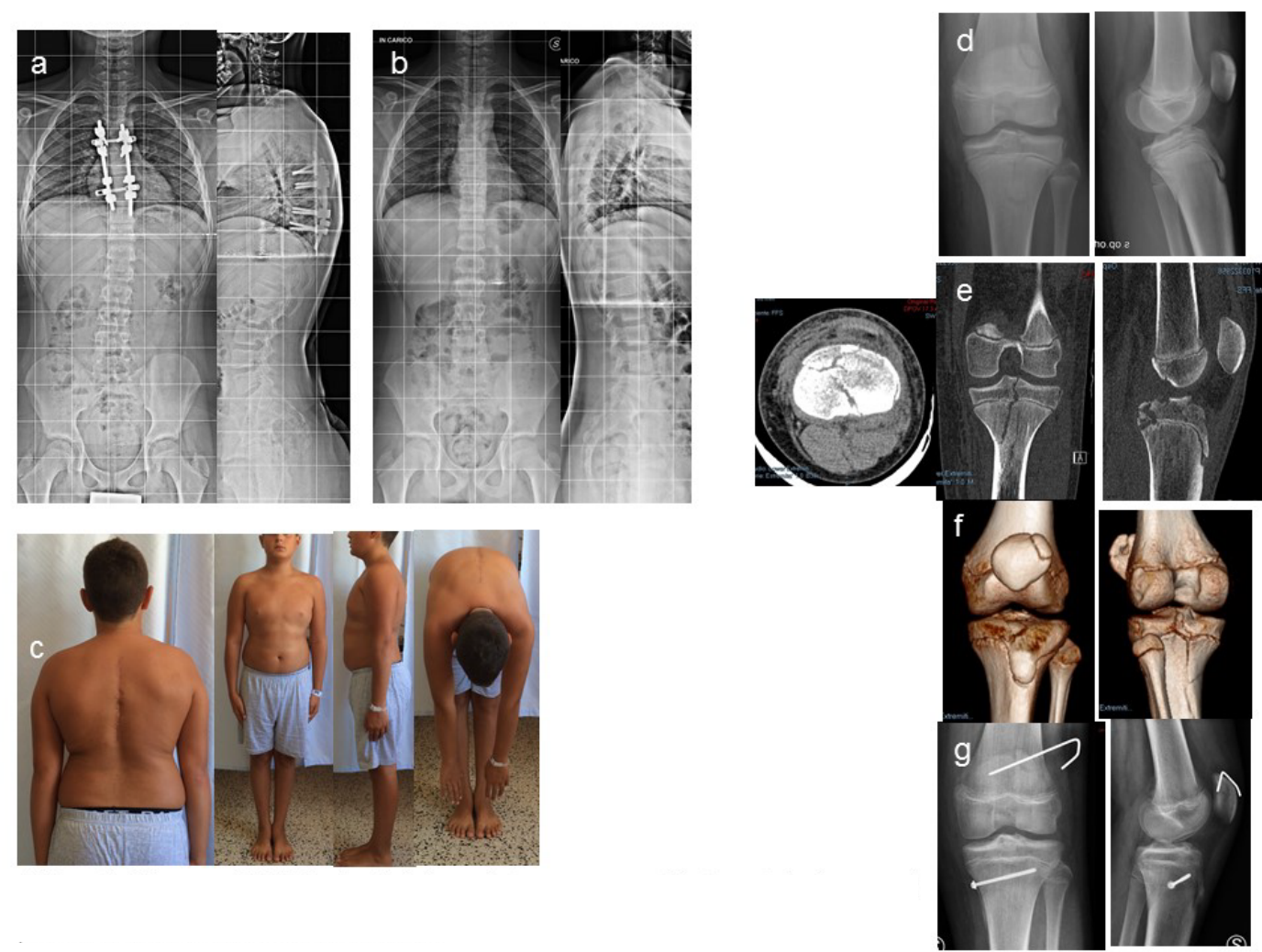

Figure 3. CL 9 months follow up a: T6-T7-T8 arthrodesis is complete on X-rays exam; b: instrumentation is removed; c: clinical appearance; d-g: six months after instrumentation removal, the patient has patella and tibial plated fracture in another motorbike race accident 
surface areas for contact with high forces. Immature vertebral bodies are also wedge shaped, thus creating a natural kyphosis and predisposition to compression fractures [12].

The definition of vertebral burst fracture is derived from Denis' description [13] including fracture of one or both endplates, disruption of the osteoligamentous anterior and middle column and bony retropulsion into the spinal canal. These injuries are the result of a flexion-axial load placed on the spinal column. Multiple studies have been conducted to investigate operative versus non operative management indications $[14,15]$, the relationship between canal compromise and neurologic deficit [16-20] and long term outcomes of different treatments [21]. The majority of these studies are limited to adult patients, while studies on adolescent and paediatric patients are sporadic $[22,23]$. Although the literature provides general guidelines for treating adult patients with thoracic burst fracture, the choice of treatment remains controversial; this is moreover true in the young patients, as there is little evidence supporting best treatment options [24]. After Denis classification the burst fractures have been divided into "stable" and "unstable": in the "stable" burst fractures the centrum of the vertebra is compressed and the posterior wall is fractured, but the remaining posterior structures, such as the articular processes and the intact ligaments, function as a posterior tension band and resist the compression forces; the "unstable" burst fractures are characterized by lesion of the posterior column [22].

Denis [13] asserted that neurologically intact patients with unstable burst fractures require surgical stabilization to prevent neurologic deterioration or worsening kyphosis.

The fracture of our patients was unstable as left pedicle and facet joint complex was completely separated from the body of the vertebra by a fracture of its base of implant and is dislocated inside vertebral canal, posing a potential treat of compression lesion on spinal cord. This fracture pattern with a pedicle and facet joint displaced inside the canal has never been described before in a paediatric patient, to our knowledge.

Treatment strategy was stabilizing T7 fracture while removing the displaced fragment from vertebral canal avoiding the risk of secondary spinal cord injury.

Instrumentation was extended 2 levels above and 2 levels below T7 fracture to obtain effective stabilization. Short instrumentation, extended only one level above and below unstable lesion, is unable to prevent progression of deformity in children and adolescents, as well as in adults [22,25].

After surgery we keep the patient braced with cast and then with a brace for a period of three months, according to our experience with instrumented arthrodesis in spine deformities correction surgery [26], to assure complete posterior spinal fusion, and to grant anterior support to posterior instrumentation, as T7 lesion was associated with T5, T6, T8, T9, T10 vertebral body compression fractures. T6 and T7 laminotomy seems have no effect on stabilization, as after 9 months arthrodesis was complete without increase of dorsal kyphosis.

Magnus et al. [27] found that in vertebral fractures in patients younger than 16 years at follow up there was no reduced disk height and no increased scoliosis or kyphosis. Younger children have also a modelling potential, restoring the height of the fractured vertebral body with growth.

Similar favorable outcome is reported by Parisini et al. [22] in a case mix of 20 patients younger than 16 years with compression fractures or two-column burst fractures without neurological deficits that did not developed kyphosis or scoliosis over $10^{\circ}$ Cobb in 18 years follow up. Moller et al. [14] found that in a late adolescence (16-18 years old patients) thoracic and lumbar vertebral fractures with no or minor neurological deficits have favorable long-term outcome, even if no modelling capacity of the fractured vertebral body remains in this age.

\section{Conclusions}

As children motorbike use and competitions are becoming more and more diffuse, motorbike accidents with resulting lesions are more common, including severe spine fractures. The patient of this case report is included in a cohort of 6 cases of thoracic fractures caused by injuries during young riders motorbike competitions in patients under 15 years of age. Another one with burst fracture has been treated similarly, the other 4 patients have been treated by cast/bracing without surgery for a mean period of 3 months (3-5 months). Even if thoracic vertebral burst fractures incidence in paediatric patients is reported low in literature, this occurrence is not rare [9] in case of spine injuries in young motorbike riders. There are no defined guidelines for treatment of thoracic spine fractures in children: priority is treating associated nervous lesions and stabilizing unstable fractures, even without associated nervous deficits, and in these cases, surgery is almost mandatory. Stable thoracic fractures in children are effectively treated by bracing.

Thoracic fractures with no or minor nervous impairment in paediatric patients seems to have a predominantly favorable long-term outcome.

\section{References}

1. Parent S, Dimar J, Dekutoski M, Roy Beaudry M (2010) Unique features of pediatric spinal cord injury. Spine 35: S202-S208. [Crossref]

2. Akbarnia BA (1999) Pediatric spine fractures. Orthop Clin North Am 30: 521-536. [Crossref]

3. Dogan S, Safavi-Abbasi S, Theodore N, Chang SW, Horn EM, et al. (2007) Thoracolumbar and sacral spinal injuries in children and adolescents: A review of 89 cases. J Neurosurg 106: 426-433. [Crossref]

4. Cirak B, Ziegfeld S, Knight VM, Chang D, Avellino AM, et al. (2004) Spinal injuries in children. J Pediatr Surg 39: 607-612. [Crossref]

5. Carreon LY, Glassman SD, Campbell MJ (2004) Pediatric spine fractures: A review of 137 hospital admissions. J Spinal Disord Tech 17: 477-482. [Crossref]

6. Junkins EP jr, Stotts A, Santiago R, Guenther E (2008) The clinical presentation of pediatric thoracolumbar fractures: A prospective study. J Trauma 65: 1066-1071. [Crossref]

7. Rennie L, Court-Brown CM, Mok JY, Beattie TF (2007) the epidemiology of fractures in children. Injury 38: 913-922. [Crossref]

8. Sawyer JR, Beebe M, Creek AT, Yantis M, Kelly DM, et al. (2012) Age -related patterns of spine injury in children involved in all-terrain vehicle accidents. $J$ pediatr Orthop 32: 435-439. [Crossref]

9. Daniels AH, Sobel AD, Eberson CP (2013) Pediatric Thoracolumbar Spine Trauma. $J$ Am Acad Orthop Surg 21: 707-716. [Crossref]

10. Balthrop PM, Nyland JA, Roberts CS, Wallace J, Van Zyl R, et al. (2007) Orthopedic trauma from recreational all-terrain vehicle use in central Kentucky: a 6-year review. $J$ Trauma 62: 1163-1170. [Crossref]

11. Dietz MJ, Lavender C, Emery SE, Clovis N, Shuler FD, et al. (2012) All terrain vehicle related orthopedic trauma in North Central West Virginia: an 8-year review of a level I trauma center. J Orthop Trauma 26: e83-e87. [Crossref]

12. Hadley MN, Zambramski JM, Browner CM, Rekate H, Sonntag VK (1988) Pediatric spinal trauma: review of 122 cases of spinal cord and vertebral column injuries. $J$ Neurosurg 68: 18-24. [Crossref]

13. Denis F, Armostrong GW, Searls K, Matta L (1984) Acute thoracolumbar burst fractures in the absence of neurologic deficit. A comparison between operative and nonoperative treatment. Clin Orthop Relat Res. 89: 142-149. [Crossref] 
14. Moller A, Hasserius R, Redlund-Johnell I, Ohlin A, Karlsson MK (2007) Nonoperatively treated burst fractures of the thoracic and lumbar spine in adults: a-23 to 41 year follow -up. Spine J 7: 701-707. [Crossref]

15. Wood K, Buttermann G, Mehbod A, Garvey T, Jhanjee R, et al. (2003) Operative compared with non opertaive treatment of a thoracolumbar burst fracture without neurologic deficit. A prospective randomized study. J Bone Joint Surg Am 85-A: 773781. [Crossref]

16. de Klerk LW, Fontijne WP, Stijnen T, Braakman R, Tanghe HL, et al. (1988) Spontaneous remodelling of the spinal canal after conservative management of thoracolumbar burst fractures. Spine (Phila Pa 1976) 23: 1057-1060. [Crossref]

17. Delfino HL, Canto FR (2007) Low thoracic and lumbar burst fractures: radiographic and functional outcomes. Eur Spine J 16: 1934-1943. [Crossref]

18. Hashimoto T, Kaneda K, Abumi K (1988) Relationship between traumatic spinal canal stenosis and neurologic deficits in thoracolumbar burst fractures. Spine (Phila Pa 1976) 13: 1268-1272. [Crossref]

19. Keene JS, Fischer SP, Vanderby R Jr, Drummond DS, Turski PA (1989) Significance of acute posttraumatic bony encroachment of the neural canal. Spine (Phila Pa 1976) 14: 799-802. [Crossref]

20. Mohanty SP, Venkatram N (2002) Does neurologic recovery in thoracolumbar and lumbar burst fractures depend on the extent of canal compromise? Spinal Cord 40: 295-299. [Crossref]
21. Shen WJ, Lui TJ, Shen YS (2001) Nonoperative treatment versus posterior fixation for thoracolumbar junction burst fractures without neurologic deficit. Spine (Phila Pa 1976) 26: 1038-1045. [Crossref]

22. Parisini P, Di Silvestre M, Greggi T (2002) Treatment of spinal fractures in children and adolescents: long-term results in 44 patients. Spine (Phila Pa 1976) 27: 1989-1994 [Crossref]

23. Thomas KC, Lalonde F, O’Neil J, Letts RM (2003) Multiple level thoracolumbar burst fractures in teenaged patients. J Pediat Orthop 23: 119-123. [Crossref]

24. Vander Have KL, Caird MS, Gross S, Farley FA, Graziano GA, et al. (2009) Burst fractures of the thoracic and lumbar spine in children and adolescents. $J$ Pediatr Orthop 29: 713-719. [Crossref]

25. Mc Lain RF, Sparling E, Benson DR (1993) Early failure of short-segment pedicle instrumentation for thoracolumbar fracture. A preliminary report. $J$ Bone Joint Surg Am 75: 162-167. [Crossref]

26. Crostelli M, Mazza O, Mariani M, Mascello D (2013) Treatment of severe scoliosis with posterior-only approach arthrodesis and all-pedicle screw instrumentation. Eur Spine J 22: S808-S814. [Crossref]

27. Karlsson MK1, Moller A, Hasserius R, Besjakov J, Karlsson C, et al. (2003) A modeling capacity of vertebral fractures exists during growth- an up to 47-year follow up. Spine (Phila Pa 1976) 28: 2087-2092. [Crossref]

Copyright: $\odot 2018$ Crostelli M. This is an open-access article distributed under the terms of the Creative Commons Attribution License, which permits unrestricted use, distribution, and reproduction in any medium, provided the original author and source are credited. 